\title{
Bone Marrow Granulomatosis in Acute Q Fever
}

\author{
Review began 09/30/2021 \\ Review ended 10/13/2021 \\ Published 10/14/202 \\ (c) Copyright 2021 \\ Carvalho et al. This is an open access \\ article distributed under the terms of the \\ Creative Commons Attribution License CC- \\ BY 4.0., which permits unrestricted use, \\ distribution, and reproduction in any \\ medium, provided the original author and \\ source are credited.
}

\author{
Joana Azevedo Carvalho ${ }^{1}$, Susana Pereira ${ }^{2}$, Leonor Boavida ${ }^{1}$, Nuno Gião ${ }^{3}$, Ana Bastos Furtado ${ }^{1}$
}

1. Department of Internal Medicine IV, Hospital Professor Doutor Fernando Fonseca, Amadora, PRT 2. Department of Hematology, Hospital Santo António dos Capuchos - Centro Hospitalar Lisboa Central, Lisbon, PRT 3. Department of Pathologic Anatomy, Hospital Santo António dos Capuchos - Centro Hospitalar Lisboa Central, Lisbon, PRT

Corresponding author: Joana Azevedo Carvalho, j_carvalho@netcabo.pt

\begin{abstract}
Reported cases of $\mathrm{Q}$ fever in people living in urban areas after occasional contact with farm animals or infected pets such as dogs and cats have been increasing. The diagnosis of $\mathrm{Q}$ fever is usually laborious due to unspecific and variable clinical manifestations. The most common clinical presentation is an influenza-like illness with varying degrees of pneumonia and hepatitis. Acute hepatitis is more frequent than pneumonia in countries where the disease is endemic, such as in Portugal.
\end{abstract}

We report a case of acute $\mathrm{Q}$ fever with hepatic and bone marrow involvement presented as fever of unknown origin (FUO) in a 56-year-old sportive hunter man. Typical fibrin ring granulomas (doughnut granulomas) were found in the bone marrow biopsy and were essential for the diagnosis.

Bone marrow involvement is considered a rare manifestation of $\mathrm{Q}$ fever. Coxiella infection activates a granulomatous inflammatory response that can lead to persistent immune cell activation. Doughnut granulomas are not pathognomonic but they are highly specific for the diagnosis of $\mathrm{Q}$ fever.

Categories: Internal Medicine, Pathology, Infectious Disease

Keywords: fever of unknown origin, fibrin ring granuloma, doughnut granuloma, coxiella burnetii, q fever

\section{Introduction}

There has been an increase in reports of sporadic cases of $\mathrm{Q}$ fever in people living in urban areas after occasional contact with farm animals or infected pets such as dogs and cats [1]. Coxiella burnetii infection in humans can be acute or chronic and long-term sequelae have been considered as a third category of the disease. $\mathrm{Q}$ fever is usually asymptomatic or manifests as a mild disease with spontaneous recovery. The most common clinical presentation is an influenza-like illness with varying degrees of pneumonia and hepatitis. Endocarditis is the most frequent chronic presentation [2].

Patients with hepatic involvement can however present with prolonged "fever of unknown origin" (FUO) associated with elevation of liver enzymes and hepatomegaly without jaundice. Liver biopsy shows granulomatous hepatitis with typical "doughnut" granulomas. This presentation is more frequent than pneumonia in countries where the disease is endemic such as France, Spain, Israel, Taiwan, and Portugal $[3,4]$.

We present a case of a sportive hunter who presented with an acute $\mathrm{Q}$ fever with typical hepatic involvement associated with a significant systemic inflammatory response and granulomatous infiltration of the bone marrow.

\section{Case Presentation}

A 56-year-old man presented to the emergency department with a two-week history of fever with rigors, night sweats, myalgia, asthenia, and anorexia. The fever had a partial response to acetaminophen one gram every eight hours. The patient had a history of hypertension and diabetes mellitus type II, with optimal control with oral medication. He was a sportive hunter that lived in a Portuguese rural area, had a vaccinated dog, and had no recent travel history. There was no family or sexual history of note.

Physical examination was unremarkable except for a slight increase in heart rate (108 bpm). Laboratory investigation revealed a serum C-reactive protein of $30.36 \mathrm{mg} / \mathrm{dL}$ without leukocytosis, elevated erythrocyte sedimentation rate (ESR) of $101 \mathrm{~mm} / \mathrm{h}$, an acute liver injury with normal bilirubin (AST 223U/L, ALT 224U/L, GGT 737U/L, FA 303.01U/L, total bilirubin $1.09 \mathrm{mg} / \mathrm{dL}$ ) with a spontaneous elevation of INR of 1.4 and hypoosmolar hyponatremia (Na 130mmol/L) - (Table 1). Viral serologies including HIV, hepatitis A, B, C, cytomegalovirus, and SARS-CoV-2 were negative. A false positivity for EBV (IgM and IgG VCA) was confirmed by a blood polymerase chain reaction (PCR) assay. Blood and urine cultures were negative. Thoracic radiography showed a diffuse interstitial infiltrate and the thoracoabdominal computed tomography (CT) scan showed diffuse bronchial thickening and hepatosplenomegaly associated with light pleural and peritoneal serositis. Small adenopathies (periaortic and in the hepatic hilus) with the largest 


\section{Cureus}

diameter of $11 \mathrm{~mm}$ were also reported.

\begin{tabular}{|c|c|c|c|c|c|}
\hline & Admission & $\begin{array}{l}\text { One week after } \\
\text { admission }\end{array}$ & $\begin{array}{l}\text { Three weeks after } \\
\text { admission }\end{array}$ & $\begin{array}{l}\text { One month after } \\
\text { admission }\end{array}$ & $\begin{array}{l}\text { Three months after } \\
\text { admission }\end{array}$ \\
\hline $\begin{array}{l}\text { Hemoglobin } \\
(\mathrm{g} / \mathrm{dL})\end{array}$ & 11.7 & 10.2 & 13.5 & 12.5 & 15.3 \\
\hline Hematocrit (\%) & 34.6 & 32.4 & 40.1 & 38.2 & 44.9 \\
\hline $\begin{array}{l}\text { Leukocytes } \\
\left(\times 10^{9} / \mathrm{L}\right)\end{array}$ & 9.9 & 4.9 & 13.8 & 14.9 & 8.7 \\
\hline $\begin{array}{l}\text { Neutrophils } \\
\left(\times 10^{9} / \mathrm{L}\right)\end{array}$ & 7.3 & 2.9 & 9.6 & 9.7 & 4.1 \\
\hline Platelets $\left(\times 10^{9} / \mathrm{L}\right)$ & 197 & 101 & 684 & 442 & 201 \\
\hline Sodium (mmol/L) & 130 & 136 & 136 & 139 & 143 \\
\hline AST (U/L) & 223 & 61 & 24 & 17 & 24 \\
\hline ALT (U/L) & 224 & 94 & 37 & 19 & 19 \\
\hline ALP (U/L) & 303 & 210 & * & 103 & 88 \\
\hline LDH (U/L) & 386 & 231 & 141 & 136 & 153 \\
\hline GGT(U/L) & 737 & 231 & 87 & 65 & 38 \\
\hline $\begin{array}{l}\text { Total bilirubin } \\
\text { (mg/dL) }\end{array}$ & 0.68 & * & 0.20 & * & * \\
\hline Albumin (g/dL) & 3.42 & 2.11 & 4.16 & * & 4.51 \\
\hline CPR (mg/dL) & 30.4 & 21.6 & 8.1 & 5.8 & 0.1 \\
\hline ESR (mm/h) & 101 & 100 & 56 & 5.8 & 0.1 \\
\hline Ferritin (ng/mL) & 7,662 & 4,300 & * & * & 171 \\
\hline ACE (U/L) & * & * & 163.7 & 85.0 & * \\
\hline
\end{tabular}

\section{TABLE 1: Laboratory blood test results}

*, Not available; AST, aspartate aminotransferase; ALT, alanine aminotransferase; ALP, alkaline phosphatase; LDH, lactate dehydrogenase; GGT, gammaglutamyl transferase; CPR, C-reactive protein; ESR, erythrocyte sedimentation rate; ACE, angiotensin-converting enzyme

The patient was admitted to an internal medicine department for further investigation. Empirical antibiotic therapy with IV ceftriaxone was started with no response and the patient maintained fatigue and daily highgrade fever (maximum temperature $39 \cdot 1^{\circ} \mathrm{C}$ ).

Multiple infectious causes were excluded by serology and/or urinary antigen tests, such as Mycoplasma pneumoniae, Legionella pneumophila, Rickettsia spp, Brucella, Leptospira, Bartonella, Borrelia burgdorferi Franciella tularensis, Ehrlicia chanffensis and Chlamydia pneumoniae. PCR for Mycobacterium tuberculosis in the bronchoalveolar lavage and interferon-gamma release assay was also negative. C. burnetii serologies were inconclusive due to the low title of phase I IgM with a negative phase II IgM and IgG. Cardiac vegetations were excluded by transthoracic echocardiogram.

Further blood tests revealed a low title of anti-nuclear antibodies (ANA) (1/160) with a fine speckled pattern, low title of anti-dsDNA, low levels of C4 (3.8mg/dL) with normal levels of C3, elevated serum angiotensin-converting enzyme (ACE) levels of $163.72 \mathrm{U} / \mathrm{L}$ and high levels of ferritin $(7,662 \mathrm{ng} / \mathrm{mL})$. No other autoantibodies related to lupus, autoimmune hepatitis, or vasculitis were positive. Thoracic CT scan excluded hilar or mediastinal lymphadenopathies. Prostatic-specific antigen and alpha-fetoprotein were normal.

Bone marrow cultures were sterile. Myelogram and bone marrow biopsy revealed a population of $10 \%$ of polyclonal CD138+ plasma cells associated with diffuse granulomas with a central lipid vacuole (Figures 1 , 


\section{Cureus}

2).

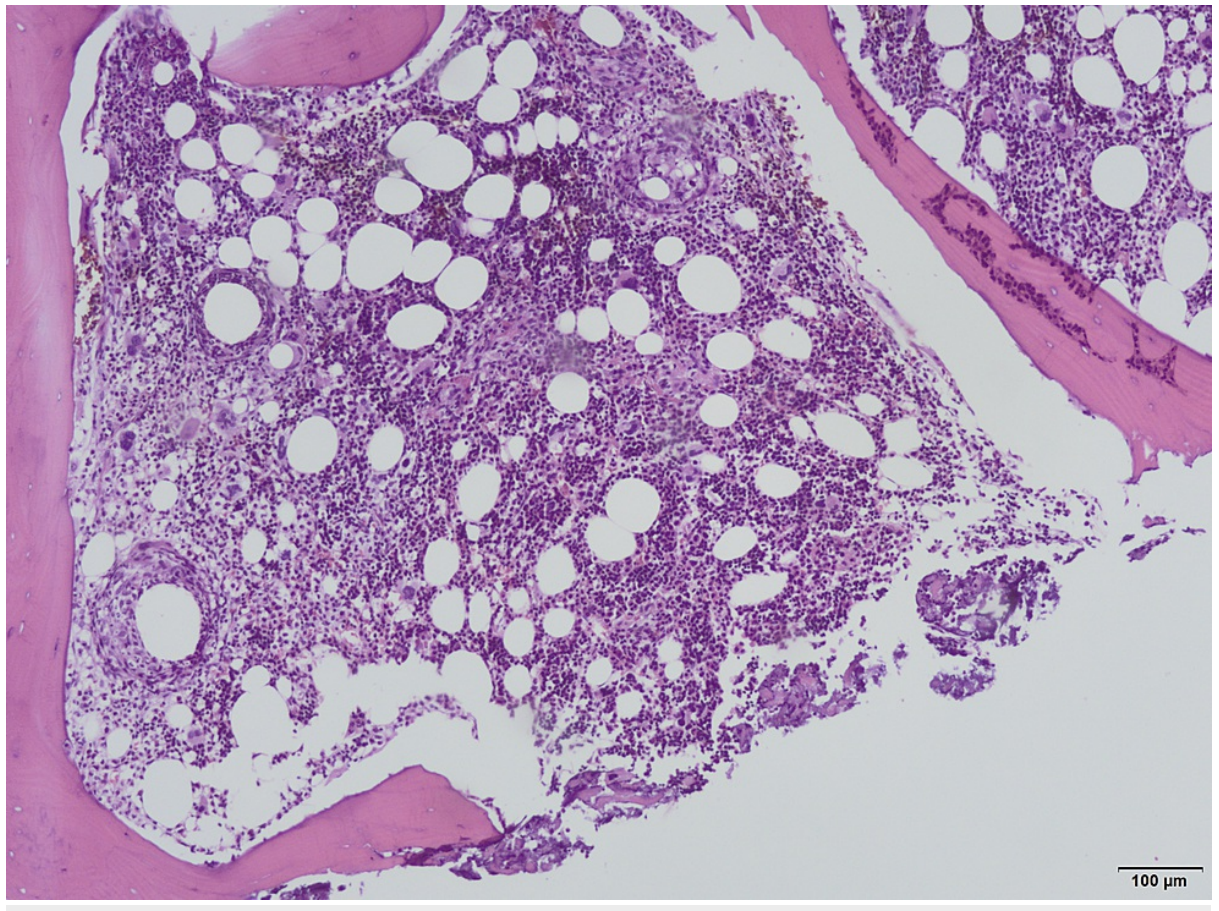

FIGURE 1: Bone-marrow specimen demonstrating multiple fibrin-ring granulomas (hematoxylin \& eosin stain; x100)

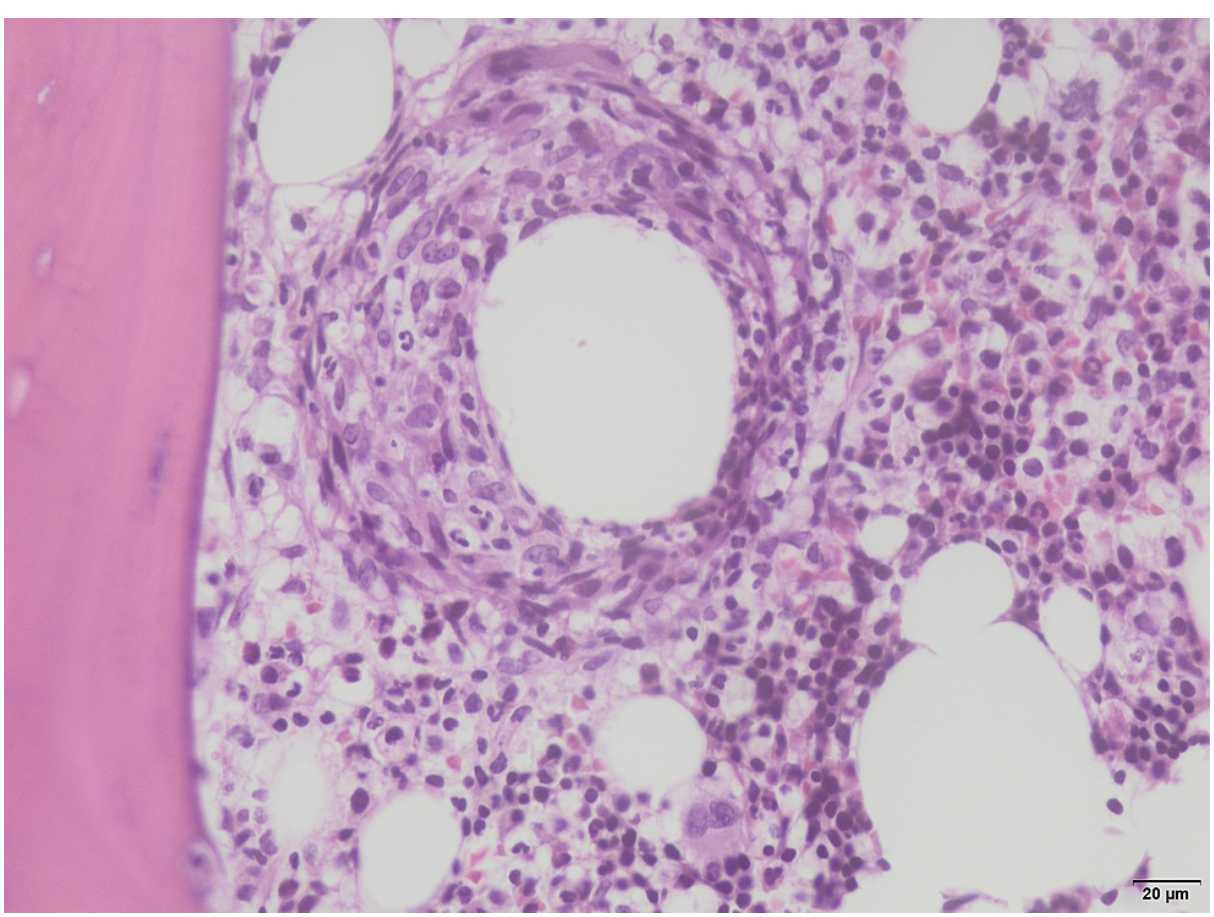

FIGURE 2: Higher magnification of bone marrow specimen showing non-necrotizing granuloma with a central fatty vacuole and the surrounding macrophages (hematoxylin \& eosin stain; $\mathbf{x 4 0 0 )}$

Empirical doxycycline was started due to the suspicion of zoonosis. The patient's condition evolved with hypercalcemia $(11.5 \mathrm{mg} / \mathrm{dL})$ and persistent inflammation with high ESR and ferritin $(3,240 \mathrm{ng} / \mathrm{mL})$.

Dexamethasone $8 \mathrm{mg} /$ day was administered for three days followed by slow tapering for two weeks, 
with rapid normalization of calcium levels and reduction of the inflammatory parameters and ACE (84.95U/L). C. burnetii serologies were repeated. The diagnosis of acute $\mathrm{Q}$ fever was confirmed by elevated titers of IgG phase II (3,200), IgM phase II titer (50), and IgM phase I (100). Doxycycline therapy was continued for a total of 14 days. The patient's condition improved progressively and normalization of inflammatory parameters, ACE levels, and liver function tests was achieved. After three months, the patient was asymptomatic and the 18-F-FDG PET-CT scan excluded potential vascular or cardiac involvement.

\section{Discussion}

The diagnosis of $\mathrm{Q}$ fever is usually laborious due to unspecific and variable clinical manifestations. The diagnosis of $Q$ fever should be considered in patients who have risk factors for the disease, for instance, contact with farm animals, rural living downwind from farms, travel to endemic areas, etc., and signs and symptoms of $\mathrm{Q}$ fever infection. The disease is often diagnosed only after other diagnoses have been systematically excluded. Significantly positive serologies may take three to four weeks to become evident and only 39 of 100 people presenting with $Q$ fever are positive in their first test $[1,3,4]$. As occurred in this case, the diagnosis of primary infection was made by the detection of a four-fold increase in phase II IgG or IgM antibodies between two serum samples taken three to six weeks apart. Generally, titers of phase II IgG of $>200$ and/or IgM of $>50$ are considered significant for the diagnosis of primary $\mathrm{Q}$ fever infection.

Biological markers of autoimmunity are frequently present in acute $Q$ fever. Anti-smooth muscle antibodies, antineutrophil cytoplasmic antibodies, and antinuclear and antiphospholipid antibodies have all been detected during acute $\mathrm{Q}$ fever [4]. The latter, together with lupus anticoagulant, may also be found and are associated with acute $\mathrm{Q}$ fever endocarditis and/or the development of persistent infection. In this case, the patient presented a positive ANA and anti-dsDNA at low titers that were interpreted as an epiphenomenon. No systemic symptoms of lupus developed after the treatment of the infection.

The clinical presentation can be very pleomorphic, though acute hepatitis is a common form of presentation of acute $\mathrm{Q}$ fever. Three major forms of hepatitis may be encountered: 1 ) an infectious hepatitis-like form of hepatitis with hepatomegaly but seldom with jaundice, 2) clinically asymptomatic hepatitis, and 3) prolonged fever of unknown origin with characteristic granulomas on liver biopsy.

Bone marrow examination should always be performed as part of the evaluation for fever of unknown origin and, in this case, was fundamental for the diagnosis. Granulomas are frequently found in infectious diseases such as tuberculosis, syphilis, histoplasmosis, and brucellosis. Bone marrow lesions associated with $\mathrm{Q}$ fever are rarely reported. Different types of granulomas have been seen in histologic sections of patients with $Q$ fever, ranging from proliferative granulomas and necrotized granuloma to a more specific "doughnut granuloma." Doughnut granuloma is characterized by a lipid vacuole in the center of the granuloma, rimmed by polymorphonuclear leukocytes and epithelioid cells. This type of granuloma is frequently described but not pathognomonic of $Q$ fever. It has also been described in patients with brucellosis, leishmaniasis, infectious mononucleosis, and cytomegalovirus infection [4-6].

The elevated levels of ACE can be explained by the total body granuloma load. High ACE levels are commonly associated with sarcoidosis. However, they can also be found in other conditions such as tuberculosis and other infectious granulomata, liver disease, lymphoma, diabetes, hyperthyroidism, or even as a benign familial condition [7]. In fact, $Q$ fever should be considered a granulomatous disease. In this case, normalization of ACE levels after $\mathrm{Q}$ fever treatment seems to support the association between this biomarker and the granulomatous response during Coxiella infection.

Some cases of granulomatous hepatitis have prolonged febrile illness with poor response to antibiotics that seem to result from a persistent immune cell activation. Moderate doses of steroids can be useful in these patients [8].

The prognosis of acute $\mathrm{Q}$ fever is generally good. Risk factors for chronicity have been reported: immunosuppression, valvulopathy, pregnancy, and prosthetic joints. Eldin et al. recommend a close serological follow-up of all patients with C. burnetii primary infection at three and six months for early detection of an increase in antibody titers and the performance of an 18 F-FDG PET-CT.

\section{Conclusions}

Q fever is a zoonotic disease caused by C. burnetii that occurs worldwide and should be considered in the differential diagnosis of FUO. There is considerable scope for misdiagnosis so that a detailed clinical history (including environmental exposures) and a systematic diagnostic approach are crucial. Bone marrow involvement and its clinical consequences are rarely described in the literature. This case highlights a new perspective of $\mathrm{Q}$ fever as a systemic granulomatous disease.

\section{Additional Information}

\section{Disclosures}


Human subjects: Consent was obtained or waived by all participants in this study. Conflicts of interest: In compliance with the ICMJE uniform disclosure form, all authors declare the following: Payment/services info: All authors have declared that no financial support was received from any organization for the submitted work. Financial relationships: All authors have declared that they have no financial relationships at present or within the previous three years with any organizations that might have an interest in the submitted work. Other relationships: All authors have declared that there are no other relationships or activities that could appear to have influenced the submitted work.

\section{Acknowledgements}

The authors would like to thank Dr. Ana Santos (Centro de Estudos de Vetores e Doenças Infeciosas Doutor Francisco Cambournac, Águas de Moura, PRT) for performing serological tests for the detection of Coxiella burnetii antibodies. The authors would also like to show their gratitude to Dr. Catarina Favas and Dr. José Delgado Alves (Department of Internal Medicine IV, Hospital Professor Doutor Fernando Fonseca, Amadora, PRT) for proofreading and comments on the manuscript.

\section{References}

1. Maurin M, Raoult D: Q fever. Clin Microbiol Rev. 1999, 12:518-53. 10.1128/CMR.12.4.518

2. Fournier PE, Marrie TJ, Raoult D: Diagnosis of O fever. J Clin Microbiol. 1998, 36:1823-34. 10.1128/JCM.36.7.1823-1834.1998

3. Parker NR, Barralet JH, Bell AM: Q fever. Lancet. 2006, 25:679-88. 10.1016/S0140-6736(06)68266-4

4. Eldin C, Mélenotte C, Mediannikov O, et al.: From Q fever to Coxiella burnetii infection: a paradigm change . Clin Microbiol Rev. 2017, 30:115-90. 10.1128/CMR.00045-16

5. Okun DB, Sun NC, Tanaka KR: Bone marrow granulomas in Q fever . Am J Clin Pathol. 1979, 71:117-21. 10.1093/ajcp/71.1.117

6. Kreisel F: Doughnut ring--shaped epithelioid granulomas in the bone marrow of a patient with Q fever . Int J Surg Pathol. 2007, 15:172-3. 10.1177/1066896906299074

7. Pretorius C, Ungerer J: Assessing angiotensin-converting enzyme (ACE) protein is more appropriate than ACE activity when investigating sarcoidosis. Intern Med . 2013, 173:702-3. 10.5694/mja2.5062

8. Crespo M, Sopeña B, Bordón J, de la Fuente J, Rubianes M, Martinez-Vázquez C: Steroids treatment of granulomatous hepatitis complicating Coxiella burnetii acute infection. Infection. 1999, 27:132-3. 10.1007/BF02560514 